\title{
Pedidos de patentes relacionados à cadeia agroindustrial do milho
}

\section{Patent applications related to the corn agro-industrial chain}

DOI: $10.46814 / 1 a j d v 3 n 4-023$

Recebimento dos originais: 01/05/2021

Aceitação para publicação: 31/06/2021

Ana Carolina Costa Moreira Carvalho

Especialista em Gestão Estratégica do Capital Humano

Núcleo de Excelência em Gestão do Conhecimento, Empreendedorismo e Inovação - Centro

Federal de Educação Tecnológica de Minas Gerais - CEFET-MG

Avenida dos Imigrantes, 1000 - Vargem - CEP: 37.022-560 - Varginha - MG

E-mail: anamoreira@cefetmg.br

Eduardo Gomes Carvalho

Doutor em Administração

Núcleo de Excelência em Gestão do Conhecimento, Empreendedorismo e Inovação - Centro

Federal de Educação Tecnológica de Minas Gerais - CEFET-MG

Avenida dos Imigrantes, 1000 - Vargem - CEP: 37.022-560 - Varginha - MG

E-mail: eduardogomes@ cefetmg.br

\section{RESUMO}

O milho é uma das principais culturas agrícolas brasileiras e mundiais. Diversos são os produtos derivados desta cultura: pipoca, amido, farinha, óleo, entre outros. Não obstante, diversos subprodutos contribuem para a produtividade neste complexo, como por exemplo, os gerados pela utilização da palha de milho. Este produto também é utilizado como fontede alimentação em diversos rebanhos, sendo também utilizado como produto intermediárioe interferindo na dinâmica de outras cadeias. Muito é investido em pesquisa e desenvolvimento de inovações para o plantio desta cultura, principalmente no exterior, onde esta assume papel de suma importância em determinadas economias, entre elas a norte- americana, onde inclusive este produto é um dos principais insumos da matriz energética, apresentando para um país como o Brasil, uma oportunidade de produção visando a exportação. Como qualquer outra cultura, pode-se afirmar que a qualidade do produto final ea dinâmica e produtividade deste sistema agroindustrial são fortemente influenciadas pelos insumos utilizados e pelos processos empregados na produção rural. Desta forma, inovarem processos, produtos e equipamentos passa a ser imprescindível. Diante disto, este trabalho tem o objetivo de realizar uma análise das patentes, enquanto uma das principais fontes de inovação tecnológica, disponíveis para a produção rural no sistema agroindustrial do milho. Foi realizado o levantamento das informações patentárias na base nacional de patentes do INPI. Foram analisados os registros de depósitos de pedidos de patentes e cultivares realizados ao longo de 5 anos (2007-2011). As características avaliadas foram a evolução do número de depósitos ao longo dos anos, a participação das universidades no número total de depósitos realizados, as classificações de patentes que são mais presentes e a participação por estado no número total de depósitos realizados. Além disto foram verificadas a proporcionalidade de inovações de produtos e processos. A estratégia debusca utilizada na base nacional de patentes do INPI foi a de buscar a palavra milho e analisar cada um dos depósitos de pedidos para verificar se estavam relacionadas à produção rural da cadeia agroindustrial do milho. Ao final percebeu-se que o número de depósitos de pedidos vem caindo e que a participação 
das universidades inexiste neste âmbito. É claro que a maior parte das tecnologias desenvolvidas estão relacionadas a colheita do produto.

Palavras-chave: inovação tecnológica, propriedade intelectual, milho

\begin{abstract}
Corn is one of the main agricultural crops in Brazil and worldwide. There are several products derived from this crop: popcorn, starch, flour, oil, among others. Nevertheless, several by-products contribute to productivity in this complex, such as those generated by the use of corn straw. This product is also used as a source of feed in several herds, and is also used as an intermediary product and interfering in the dynamics of other chains. Much is invested in research and development of innovations for the planting of this crop, especially abroad, where it plays an important role in certain economies, among them the U.S., where this product is one of the main inputs of the energy matrix, presenting for a country like Brazil, an opportunity to produce for export. Like any other crop, it can be said that the quality of the final product and the dynamics and productivity of this agro-industrial system are strongly influenced by the inputs used and the processes employed in rural production. Thus, innovating in processes, products, and equipment becomes essential. In view of this, this work aims to analyze patents, as one of the main sources of technological innovation available for rural production in the corn agro-industrial system. A survey of patent information was carried out at the national patent database of the INPI. The records of patent applications and cultivars made over 5 years (2007-2011) were analyzed. The characteristics evaluated were the evolution of the number of filings over the years, the participation of universities in the total number of filings, the patent classifications that are more present and the participation by state in the total number of filings. In addition, the proportionality of product and process innovations was verified. The search strategy used in the national base of patents of the INPI was to search for the word corn and analyze each of the deposits of applications to verify if they were related to the rural production of the agro-industrial chain of corn. At the end it was noticed that the number of application filings has been falling and that the participation of universities is nonexistent in this field. It is clear that most of the technologies developed are related to the harvesting of the product.
\end{abstract}

Keywords: technological innovation, intellectual property, corn.

\title{
1 INTRODUÇÃO
}

Os termos tecnologia e inovação têm sido amplamente empregados nos tempos atuais e muitas vezes de forma combinada, principalmente pela sua contribuição aos diferentes segmentos da economia. De veras é perceptível o fato de que as inovações tecnológicastêm a capacidade de impactar significativamente em diversos setores produtivos, alterando processos e produtos.

O setor do agronegócio também está propenso a tal situação. Dentro desse contexto, uma das cadeias produtivas de maior destaque no agronegócio brasileiro e mundial é a domilho. Diversos produtos são desenvolvidos a partir desta matéria-prima, tanto para fins alimentares, quanto para fins energéticos, como por exemplo, o etanol utilizado nos Estados Unidos.

A competitividade dessa cadeia produtiva somente pode ser mantida através da inserção de novos equipamentos e processos que visem melhorar os índices de qualidade e produtividade, desde 
o plantio até o processamento desse produto. Equipamentos que auxiliam no plantio e na colheita são exemplos de inovações que podem trazer competitividade para a cadeia agroindustrial do milho e, portanto, proteger tais ativos passaa ser de suma importância para as empresas.

A qualidade do produto final e a dinâmica dessa cadeia produtiva são fortemente influenciadas pelos insumos utilizados e pelos processos de produção rural do mesmo. Desta forma, esse será o espaço de análise que será considerado neste estudo. É objetivo então deste trabalho realizar um levantamento das principais inovações tecnológicas disponíveis na cadeia agroindustrial do milho que são ou podem ser utilizados na produção rural. As variáveis a serem analisadas nesta pesquisa são os depósitos de pedidos de patente realizados. As características analisadas serão as seguintes:

- a evolução do número de depósitos ao longo dos anos;

- a participação das universidades no número total de depósitos realizados;

- as classificações de patentes que são mais presentes;

- analisar a proporcionalidade de pedidos de depósitos relacionados a inovações de produtos e de processos;

- a participação por estado no número total de depósitos realizados.

As informações sobre depósitos de pedidos de patentes serão provenientes do banco de dados do site do Instituto Nacional da Propriedade Industrial - INPI.

Este trabalho trará como contribuição, verificar como os depósitos estão evoluindo ao longo dos anos de forma a apontar se ainda há oportunidades de desenvolvimento para esta cadeia. Também permitirá apontar se existem lacunas no desenvolvimento de patentes em relação às universidades e quais classificações são mais e menos exploradas. Também poderão ser identificados os estados que mais contribuem com desenvolvimento tecnológicopara esta cadeia agroindustrial, de forma a apontar para pesquisadores possibilidades de objetos para estudos de caso e pesquisas quantitativas.

Este trabalho está estruturado da seguinte forma: primeiramente será realizada uma revisão bibliográfica sobre inovação tecnológica e propriedade intelectual a fim de situar o leitor em relação ao assunto estudado, em seguida os depósitos de pedidos de patente realizados serão identificados e discutidos. Ao final, conclusões e sugestões para trabalhos futuros serão apresentadas.

\section{INOVAÇÃO TECNOLÓGICA}

\subsection{CONCEITUAÇÃO}

É necessária primeiramente uma definição mais clara dos conceitos que serão abordados neste trabalho. Deve-se deixar claro que existe uma diferença entre o que é definido como inovação tecnológica e inovação não-tecnológica, conforme descrevem Mothe e Thi (2010). Estes autores 
definem como inovações não-tecnológicas dois tipos específicos: a inovação organizacional e a inovação em marketing. A inovação organizacional é composta por três práticas: a introdução de novos ou significativamente melhorados sistemas de gestão do conhecimento, a introdução de grandes mudanças para a organização do trabalho dentro daempresa e a introdução de novas e significativas alterações no relacionamento com outras empresas ou instituições públicas. Já a inovação em marketing é composta de duas práticas: a introdução de alterações significativas no projeto ou na embalagem de bens ou serviços e a introdução de mudanças nas vendas ou métodos de distribuição. Os autores também ressaltam que inovação tecnológica é geralmente definida como a inovação abrangente de produtos e processos. Deve-se ressaltar que tais definições propostas por Mothe e Thi (2010) também estão em conformidade com o Manual de Oslo (2005).

Entretanto a diferenciação entre inovação tecnológica e não-tecnológica é importante, pois conforme salientam Silva e Plonski (1996) a inovação tecnológica existe em função de aspectos internos e externos à empresa. Internos, no que se refere à forma organizacional que permita uma comunicação contínua entre todos os níveis, aí se destacando os aspectosde planejamento estratégico, da aprendizagem e da competência. Externos, quanto ao seu relacionamento com o mercado e meio ambiente, aí incluídos os consumidores, os fornecedores, os concorrentes, e a análise constante da evolução tecnológica. Mothe e Thi (2010) afirmam que a inovação organizacional e de marketing (inovação não-tecnológica) impactam na capacidade de uma organização para inovar, mas não sobre o seu desempenho inovador.

Narvekar e Jain (2006) definem inovação como o processo de criação de algo novo na organização e, portanto, as organizações que incentivam a diversidade e riscos calculados são mais inovadoras. Esses autores apresentam uma ampla definição de inovação, que considera tanto a inovação tecnológica, quanto a inovação não-tecnológica. O Manual de Oslo (2005) afirma que uma mudança importante é a remoção da palavra "tecnológica" das definições, visto que a palavra evoca a possibilidade de que muitas empresas do setor de serviços interpretem "tecnológica" como "usuária de plantas e equipamentos de alta tecnologia”, e assim não seja aplicável a muitas de suas inovações de produtos e processos. Já Nieto (2004) afirma que os conceitos utilizados no estudo do fenômeno de inovação não são definidos usualmente com precisão e que existe uma proliferação de termos e definições que frequentemente não coincidem uns com os outros. Em seu trabalho o autor utilizou o termo "inovação tecnológica" para se referir ao processo através do qual osavanços tecnológicos são produzidos e salientou que esse conceito é associado com a idéiade um fluxo - geração, aplicação, disseminação - de tecnologias.

Entretanto, neste estudo será considerada a definição de inovação tecnológica de produto e processo apresentada no Manual de Oslo (2005). Segundo este, uma inovação tecnológica de produto 
é a implantação/comercialização de um produto com características de desempenho aprimoradas de modo a fornecer objetivamente ao consumidor serviços novos ou aprimorados. Já a inovação de processo é definida como a implantação/adoção de métodos de produção ou comercialização novos ou significativamente aprimorados. Elapode envolver mudanças de equipamentos, recursos humanos, métodos de trabalho ou umacombinação desses fatores.

O que merece destaque e deve ser ressaltado é que inovações tecnológicas têm representado uma importante fonte de vantagem competitiva. Barbieri (1997) salienta que uma das principais dimensões competitivas das empresas é a capacidade das mesmas de realizar inovações tecnológicas para responder às exigências do mercado. Narvekar e Jain (2006) também concluem em seu trabalho que a inovação tecnológica tem empurrado para frente as curvas de crescimento de muitas organizações e tem aberto novos mercados. Afirmam ainda que a mesma é a quintessência dos negócios, a chama da mudança que trazconsigo o crescimento, emoção e riqueza para a organização que inova.

Deve-se salientar, entretanto, que o objetivo deste estudo é analisar as inovações tecnológicas e por isto tal diferenciação foi apresentada, a fim de auxiliar no entendimento do espaço de análise do trabalho.

\subsection{PROPRIEDADE INTELECTUAL}

As principais variáveis deste estudo são os pedidos de patentes depositados que podem ser adotados na produção rural do milho. Tais patentes formam um subgrupo de propriedade intelectual. Desta forma, não há como não abordar tal assunto. Segundo Ferreira et al. (2009) um título de propriedade intelectual corresponde ao marco legal, mundo afora, noque se refere aos direitos relativos a determinados objetos intangíveis ou criações dointelecto humano. Oliveira et al. (2005) corroboram tal afirmação, salientando que os objetosda propriedade intelectual são as criações da mente humana, a inteligência do homem.

Smith e Hansen (2002) atentam para o fato que todos sabem (ou deveriam saber) que na nova economia do conhecimento, propriedade intelectual tem de ser gerida de forma estratégica. Os mesmos autores ainda afirmam que algumas pessoas pensam que gerenciar de maneira estratégica a propriedade intelectual é o mesmo que ter uma estratégia de propriedade intelectual ao invés de gerilas de acordo com a estratégia de negócios.

Smith e Hansen (2002) salientam ainda que propriedade intelectual é estratégica apenas na medida em que é parte das capacidades-núcleo de uma determinada empresa. Destaforma, a propriedade intelectual pode ser parte do aspecto know-what ou know-how da capacidade-núcleo. 
Como um elemento do know-what técnico único da empresa, a propriedade intelectual manifesta-se no próprio produto da empresa. Os autores sintetizam isto através de um diagrama de Venn conforme se pode observar na figura 1.

Figura 1 - Relevância da Propriedade Intelectual para a Estratégia

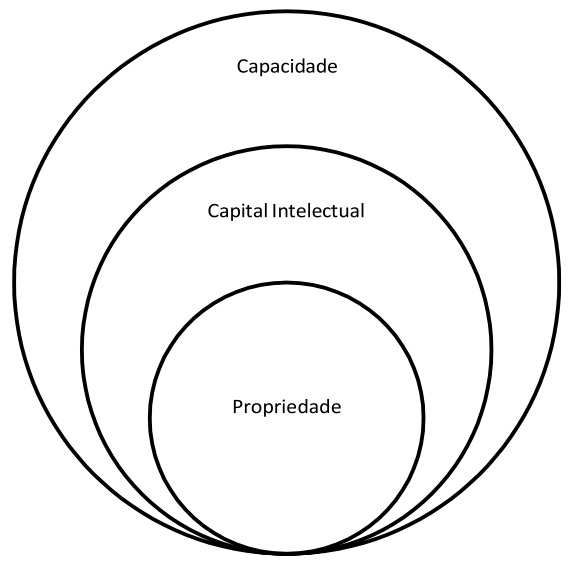

Fonte: Adaptado de Smith e Hansen (2002)

A forma de proteção intelectual que será analisada neste estudo é a patente. Amadei e Torkomian (2009) definem patente como um título de propriedade industrial sobre invenção ou modelo de utilidade. Um prêmio outorgado pelo estado como recompensa ao inventor. O registro de patente garante ao inventor certa segurança nas negociações entre ele e a parte interessada em comprar determinada tecnologia para que possa ser aplicada em algum setor industrial.

O Manual de Oslo (2005) define patente como um direito legal de propriedade sobre uma invenção, garantido pelos escritórios de patentes nacionais, sendo que a mesma confere a seu detentor direitos exclusivos (durante um certo período) para explorar a invenção patenteada.

Segundo Amadei e Torkomian (2009) no registro de patente o inventor é obrigado a revelar detalhadamente todo o conteúdo técnico do invento, sendo possível para qualquer técnico reproduzilo em laboratório.

Hanel (2006) conclui em seu trabalho que uma série de estudos demonstram que apesar de patentes serem cada vez mais percebidas em diversos setores industriais como sendo um meio pouco eficaz de apropriação dos benefícios econômicos das inovações, a utilização desta forma de proteção intelectual tem crescido. A explicação para esta aparente contradição é que as patentes são cada vez mais utilizadas para bloquear os produtos dos concorrentes, como moeda de troca no licenciamento cruzado e como prevenção ou uma defesa contra processos por infração. Por um lado, essas tendências têm levado vários economistas a questionar a premissa básica da contribuição das patentes para a inovação edifusão de novas tecnologias. 


\section{METODOLOGIA}

Esta pesquisa consistiu no levantamento das informações patentárias na base nacional de patentes do INPI. Foram analisados os registros de depósitos de pedidos de patentes e cultivares realizados ao longo de 5 anos (2007-2011).

A estratégia de busca utilizada na base nacional de patentes do INPI foi a de buscar a palavra milho e analisar cada um dos depósitos de pedidos para verificar se estavamrelacionadas à produção rural da cadeia agroindustrial do milho.

Posteriormente tais dados foram inseridos em uma planilha Excel, a fim de analisar e compilar as informações. Na próxima seção serão exibidos e discutidos os resultadosobtidos na pesquisa.

\section{RESULTADOS E DISCUSSÃO}

Foram selecionados os depósitos de pedidos realizados a partir de 2007. Deve-se ressaltar que em relação aos últimos dois anos há sigilo destes depósitos e por isso os dados referentes aos anos de 2013, 2012 e parte de 2011 não estão completos, entretanto como serão analisados os depósitos realizados no sistema do Instituto Nacional de Propriedade Industrial os mesmos foram considerados, contudo tal limitação existe. Foram encontrados 84 depósitos neste período de tempo.

Destes 84 depósitos, 57 são referentes a prioridade unionista. A quantidade de prioridades unionistas reduz conforme os anos avançam, como pode ser observado na figura 2.

Figura 2 - Prioridades Unionistas por Ano

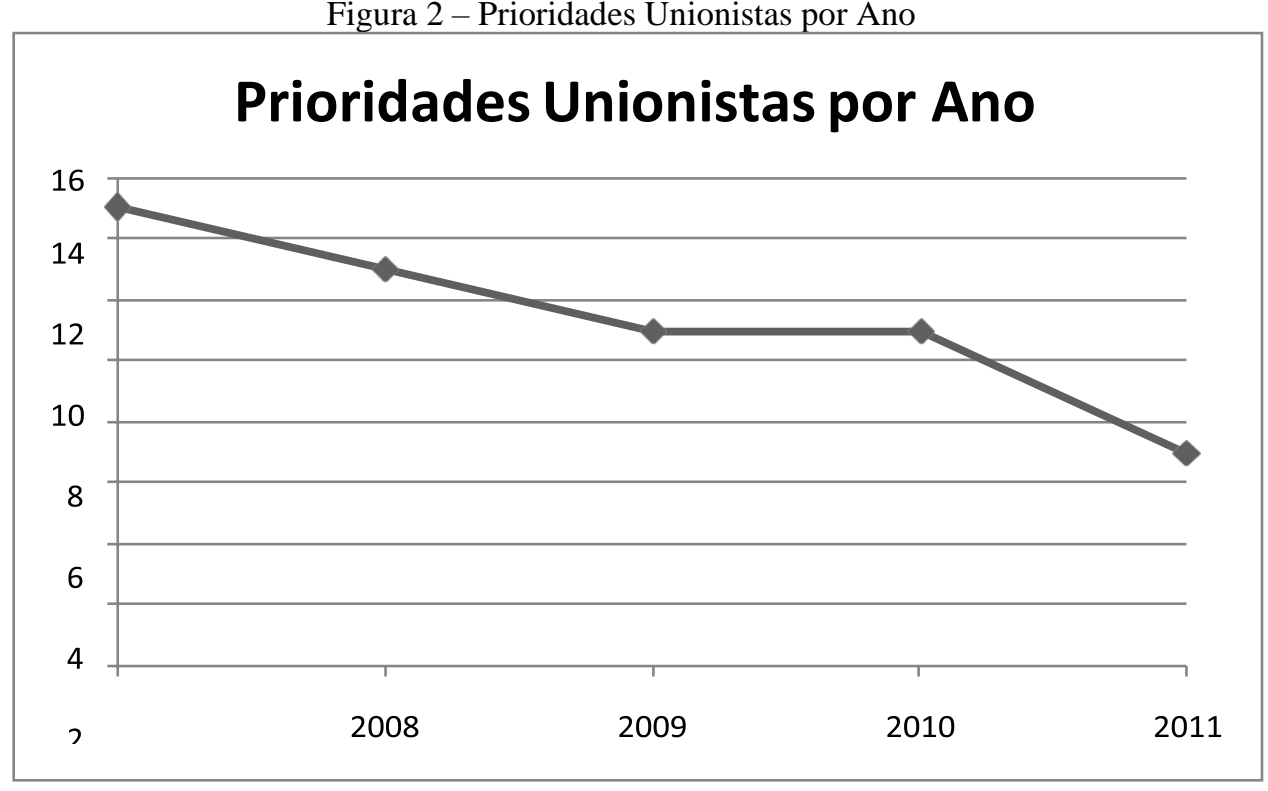

Fonte: Elaborado pelos autores

Destes 57 pedidos, com exceção de um pedido de origem européia e de um de origem argentina, os demais são oriundos dos EUA, que são o maior produtor mundial desta cultura. Entre as empresas 
que estão mais presentes destacam-se: Pioneer Hi-Bred Internacional (20 depósitos), E. I Du Pont de NemoursandCompany (15 depósitos, inclusive alguns em conjunto com a Pioneer Hi-Bred Internacional) e Monsanto Technology (11depósitos). Prioridade unionista possibilita que - ao dar entrada no pedido de patente em seu próprio país - o titular reivindique prioridade em outros países membros da Convenção da União de Paris, tendo o prazo de um ano para iniciar o processo nesses outros países, sem prejuízo para o princípio de novidade, pois fica assegurada a data do primeiro depósito.

Em relação aos 27 pedidos restantes, $74 \%$ são referentes a patentes de invenção. Patentes de invenção são avanços do conhecimento técnico que combinem atividade inventiva e aplicação industrial. $\mathrm{O}$ restante se refere a modelos de utilidade. Modelos de utilidade se referem a uma nova forma ou disposição de objeto de uso prático, com aplicação industrial, que represente melhoria funcional de produto ou processo já existente.

Em relação aos pedidos colocados por ano, há uma limitação em relação ao período de sigilo conforme salientado anteriormente. Tal informação podeser observada na figura 3.

Figura 3-Pedidos por Ano

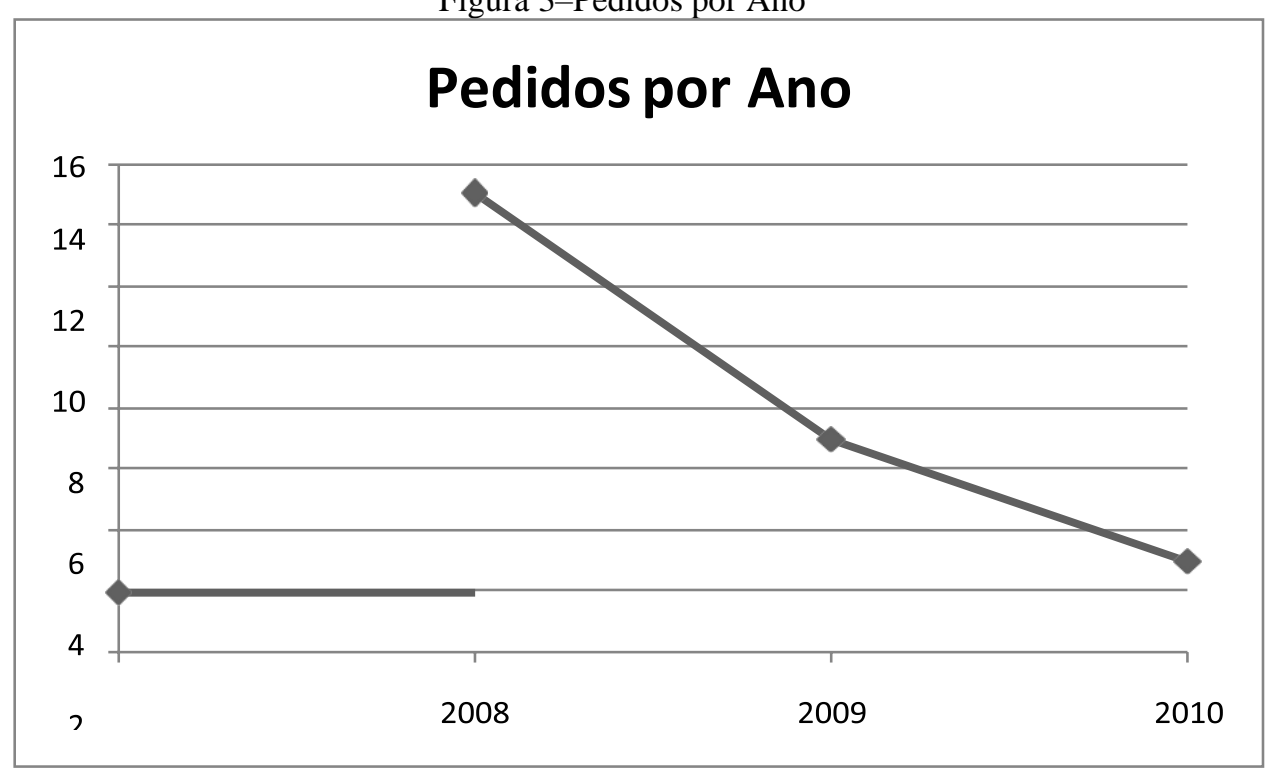

Fonte: Elaborado pelos autores

Observando a análise da variável estado de origem dos depositantes, conforme figura 4, percebe-se uma supremacia do estado de São Paulo, o que demonstra o investimento por parte das instituições deste estado em pesquisa voltada a esta cultura, já que o maior produtor é o Paraná, que está entre os que menos depositaram pedidos. Ocorre ainda um pedido que não foi depositado por instituições nacionais, mas refere-se a um depositante americano. 
Um dos objetivos da pesquisa era analisar a participação das universidades no desenvolvimento e apropriação destas inovações tecnológicas. Percebe-se que para esta cadeia produtiva não há presença das mesmas, o que evidência ser uma lacuna, principalmente para as instituições públicas paranaenses, por ser o estado com maiorprodução.

Figura 4 - Pedidos por Estado

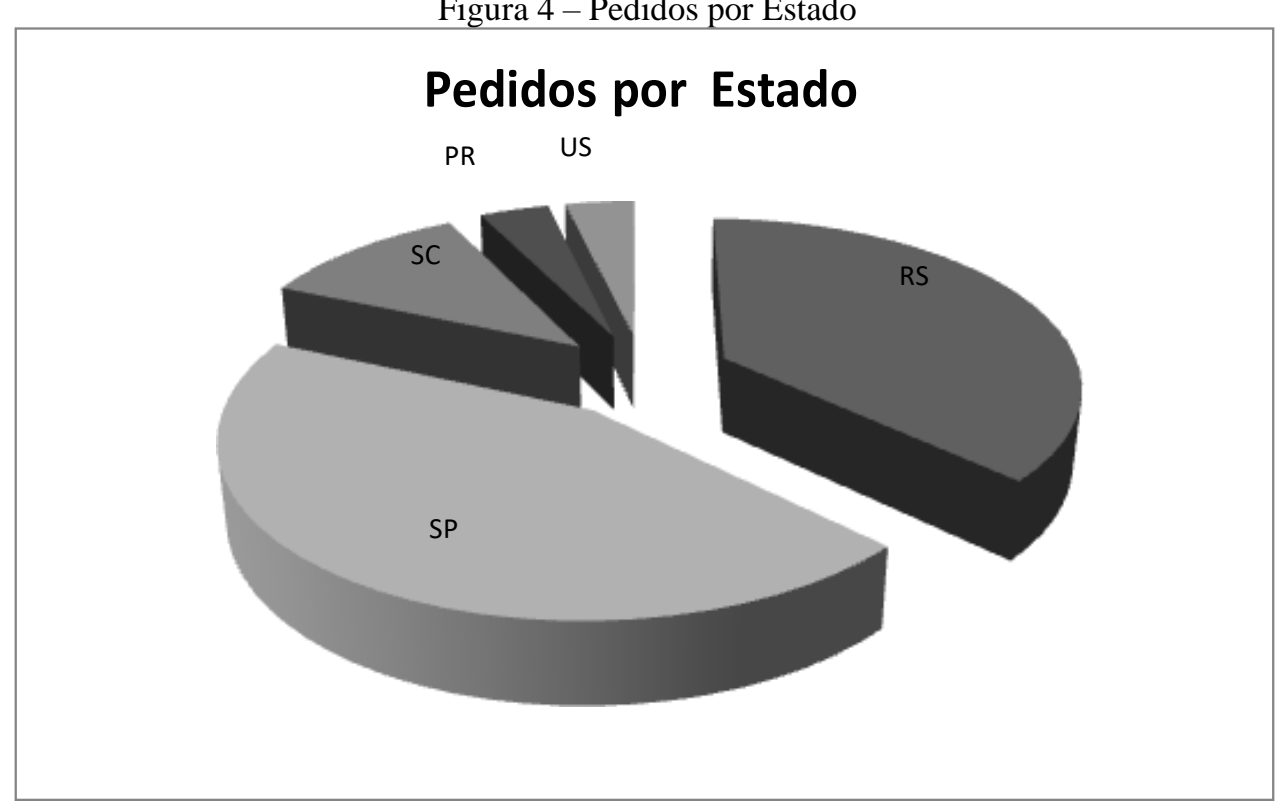

Fonte: Elaborado pelos autores

O depositante com maior quantidade de pedidos foi a empresa Marchesan Implementos e Máquinas Agrícolas Tatú S/A de Matão - SP, com 9 pedidos. Com 7 pedidos, aparece em segundo lugar a empresa Industrial Agrícola Fortaleza Importação e Exportação de Ibiruba -RS.

Em relação as inovações de produtos e processos, não existem inovações de processos em depósitos realizados no Brasil, enquanto para prioridades unionistas aproximadamente $37 \%$ dos pedidos são referentes a inovação de processos. Isso caracterizaria uma possívelcontribuição das universidades brasileiras, que não apresentaram contribuição neste escopoe seriam as instituições com maior potencial para isto, haja vista a quantidade de cursos que formam pesquisadores e profissionais destinados a atuar nesta linha, como por exemplo, cursos de engenharia.

Ao analisar as classificações dos depósitos de pedidos, percebeu-se que a que mais aparece (16 vezes) se refere ao código A01D 45/02 (Colheita de culturas verticais de milho), em segundo lugar a classificação que mais aparece (3 vezes) se refere ao código A01D 41/12 (Máquinas combinadas, por ex., Colhedeiras ou ceifadeiras combinadas com dispositivos de trilharDetalhes de máquinas combinadas) o que demonstra a preocupação maior com a questão da colheita deste tipo de grão. 


\section{CONCLUSÕES}

Foi objetivo desse trabalho realizar uma análise das potenciais inovações tecnológicas disponíveis na cadeia agroindustrial do milho que são ou podem ser utilizados na produção rural.

Em relação a evolução do número de depósitos por ano percebe-se que o houve uma tendência de queda após 2008, tanto de pedidos nacionais, quanto de prioridade unionista. Apesar da crise financeira de 2008 ser a causa provável de tal queda, deve-se considerar ainda que muitos destes pedidos encontram-se em período de sigilo. Contudo, é importante um estudo mais aprofundado para qualquer conclusão.

Em relação à participação das universidades ou instituições públicas no número total de depósitos realizados, percebe-se não haver participação deste tipo de instituição. Qualquer razão para tal situação seria mero exercício de especulação, sendo então esta uma proposta para realização de trabalhos futuros. Sugere-se neste caso procurar as instituições que depositaram pedidos similares e realizar um estudo de caso para observar porque não realizaram mais pesquisas na área, e se realizaram como apropriaram estas inovações. Entretanto, uma sugestão foi apresentada no trabalho, que é o desenvolvimento de inovações de processos, tão carentes no Brasil, pelas universidades brasileiras, até mesmo como forma de motivar profissionais da área a desenvolverem este tipo de inovação.

O estado de São Paulo se destaca em relação a participação por estado no número total de depósitos realizados. A explicação mais plausível está relacionada ao fato que entre os maiores depositantes está uma empresa oriunda deste estado, não havendo outra explicação lógica, já que o maior produtor da federação é o estado do Paraná.

Quanto às classificações de patentes que são mais presentes é perceptível a presença de tecnologias relacionadas à colheita. Novamente estudos mais aprofundados podem encontrar relação de causalidade que explicaria tais números. Neste caso, retorna-se a ausência de inovações de processos no âmbito nacional.

O resultado deste trabalho vem ao encontro da afirmação de Machado (1998) sobre a inovação das firmas de um sistema agroindustrial depender mais de avanços tecnológicos gerados noutros setores. Parayil (2003) também é respaldado neste trabalho, já que a trajetória tecnológica no setor agroindustrial aparece moldada pelos imperativos de instituições de propriedade privada, forças de mercado, finanças globais e instituições reguladoras transnacionais (e em certos casos nacionais).

Sugere-se também para estudos futuros uma análise da aplicação de algumas dessas inovações por meio de estudos de caso e também uma análise mais ampla que considereas proteções de cultivares. 


\section{REFERÊECIAS}

AMADEI, J. R. P \& TORKOMIAN, A. L V. As patentes nas universidades: análise dos depósitos das universidades públicas paulistas. Ciência da Informação. Vol. 38, número 2, p.9-18, 2009.

BARBIERI, J. C. A Contribuição da Área Produtiva no Processo de Inovações Tecnológicas. Revista deAdministração de Empresas. Vol. 37, número 1, p.66-77, 1997.

FERREIRA, A. A.; GUIMARÃES, E. R. \& CONTADOR, J. C. Patente como instrumento competitivo e comofonte de informação tecnológica. Gestão e Produção. Vol. 16, número 2, p.209$221,2009$.

HANEL, P. Intellectual property rights business management practices: A survey of the literature.

Technovation. Vol. 26, p.895-931, 2006.

INPI. Instituto Nacional da Propriedade Industrial. 2013. Disponível em: < htpp://www.inpi.gov.br >.Acesso em: 21 de maio de 2013.

MACHADO, R. T. M. Fundamentos sobre o Estudo da Dinâmica das Inovações no Agribusiness. Revista deAdministração Contemporânea. Vol. 2, número 2, p.127-141, 1998.

MOTHE, C. \& THI, T. U. N. The Link Between Non-Technological Innovations and Technological Innovation.

European Journal of Innovation Management. Vol. 13, número 3, p.313-332, 2010.

NARVEKAR, R. S. \& JAIN, K. A New Framework to Understand the Technological Innovation Process.

Journal of Intellectual Capital. Vol. 7, número 2, p.174-186, 2006.

NIETO, M. Basic Propositions for the Study of the Technological Innovation Process in the Firm. EuropeanJournal of Innovation Management. Vol. 7, número 4, p.314-324, 2004.

OCDE. Manual de Oslo - Diretrizes para a coleta e interpretação de dados sobre Inovação. $3^{\mathrm{a}}$ ed., TraduçãoFINEP, 2005, Disponível em: <http://www.mct.gov.br/index.php/content/view/4639.html>.

OLIVEIRA, L. G.; SUSTER, R.; PINTO, A. C.; RIBEIRO, N. M. \& SILVA, R. B. Informação de patentes:

ferramenta indispensável para a pesquisa e o desenvolvimento tecnológico. Química Nova. Vol. 28, suplemento,p.s36-s40, 2005.

PARAYIL, G. Mapping technological trajectories of the Green Revolution and the Gene Revolution frommodernization to globalization. Research Policy. Vol. 32, p.971-990, 2003.

SILVA, J. C. T. \& PLONSKI, G. A. Inovação Tecnológica: Desafio Organizacional. Produção. Vol. 6, número2, p.183-193, 1996.

SMITH, M. \& HANSEN, F. Managing intellectual property: a strategic point of view. Journal of Intellectual Capital. Vol. 3, número 3, p.366-374, 2002. 
WILKINSON, J. \& CASTELLI, P. G. A Transnacionalização da Indústria de Sementes no Brasil: biotecnologias, patentes e biodiversidade. Rio de Janeira: Actionaid Brasil. 2000. 